\title{
CRASHWORTHINESS REQUIREMENTS FOR COMMUTER RAIL PASSENGER SEATS
}

\author{
Kristine J. Severson \\ David C. Tyrell \\ Volpe National Transportation Systems Center \\ U.S. Department of Transportation \\ Cambridge, MA 02142 \\ Robert Rancatore \\ TIAX, LLC \\ Cambridge, MA 02142
}

\section{ABSTRACT}

Occupant experiments using instrumented crash test dummies seated in commuter rail seats have been conducted on board full-scale impact tests of rail cars. The tests have been conducted using both conventional cars and cars modified to incorporate crash energy management (CEM). Test results indicate that an improved commuter seat design could significantly reduce occupant injuries associated with collisions of CEM railcars. Commuter seats built to specific crashworthiness design requirements can mitigate the increased severity of secondary impacts associated with CEM equipment.

In a collision, the leading car or two in a CEM consist may have a more severe longitudinal crash pulse than the leading car in a conventional consist. The crash pulse associated with a leading CEM cab car results in a higher secondary impact velocity between the unrestrained occupant and the seat, when compared to a conventional cab car. This conclusion applies to both rear- and forward-facing occupants. As a result, the seat must absorb more energy, which may cause significant deformation of the seat back, preventing occupant compartmentalization. Compartmentalization is an occupant protection strategy that aims to: contain occupants between rows of seats, provide a 'friendly' impact surface, and prevent tertiary impacts with other objects.

To compartmentalize occupants during a collision, seats must be relatively stiff. To limit the forces and accelerations associated with occupant injury, the seat must be compliant, absorbing the occupant's kinetic energy as it deforms. The objective of seat design crashworthiness requirements is to strike a balance between the competing objectives of compartmentalization and minimizing occupant injury.

Work is currently on-going to design, build and test a prototype 3-passenger commuter rail seat that will improve interior crashworthiness. The first step is to develop the design requirements, which are based on a head-on collision between a CEM cab car-led train and a CEM locomotive-led train. The seat design will be evaluated using quasi-static and dynamic finite element analysis. The occupant response will be evaluated using a collision dynamics model two rows of seats and three Hybrid III $50^{\text {th }}$ percentile anthropomorphic test devices (ATDs). The seat design will be modified until the analytical models demonstrate that it meets the design requirements. Finally the prototype seat will be fabricated and tested quasi-statically and dynamically to ensure that the seat meets the design requirements.

This paper describes the performance-based requirements that the prototype commuter rail seat must meet. Performancebased requirements include occupant compartmentalization, maximum allowable injury criteria, and maximum allowable permanent seat deformations. The paper also provides strategies for designing commuter seats that are better able to manage and dissipate the energy during a secondary impact. The paper describes computer models used to determine if the seats meet the design requirements.

\section{INTRODUCTION}

Full-scale impact tests have been conducted using both conventional and CEM rail equipment. Occupant experiments have been conducted in the full-scale tests using standard, existing commuter seats, as well as seats with minor modifications. The test results indicate that, in a train-to-train collision of conventional equipment, the standard commuter seats perform reasonably well [1]. The anthropomorphic test devices (ATDs) in the forward- and rear-facing seating arrangements were compartmentalized, and the injury measurements were below the threshold values. However, a computer model of the upcoming CEM train-to-train test and results from the two-car CEM test [2] indicate that the standard 
commuter seat is not designed to withstand the increased severity of the secondary impact associated with CEM equipment.

Traditionally, commuter seat manufacturers have focused on designing seats with superior durability under operational use, with minimal maintenance required. Even though crashworthiness has not been a primary consideration in seat design, the existing seats perform reasonably well in collisions involving conventional equipment. However, as the design of the car structure is modified to better preserve the occupied areas of a train with CEM, modifications to the seat design can significantly improve the interior crashworthiness.

Commuter seats usually have a fairly simple tubular steel structure and are relatively inexpensive to fabricate. A commuter seat designed specifically for improved crashworthiness does not necessitate sophisticated technology or exotic materials. Rather, a careful tuning of the force versus deflection properties of the seat can provide a marked improvement in occupant protection.

An occupant striking a seat back, which is defined as a secondary impact, can be evaluated as a spring-mass system. The mass of an occupant impacts the seat back, which acts as a nonlinear spring. The spring behavior of the seat can be tuned to provide adequate energy absorption over a limited travel distance to decelerate the occupant without incurring lifethreatening injuries. Computer models of the occupant experiments conducted onboard the full-scale impact tests are in reasonable agreement with the test results. The following sections will describe the collision environment to which the prototype seat is being designed, the design requirements developed for the prototype seat, and suggested design strategies to meet these requirements.

\section{SECONDARY IMPACT ENVIRONMENT}

The secondary impact environment experienced by an occupant in a train collision is affected most by the type of rail car rather than the impact speed of the collision. The structural design of the rail car governs the car's acceleration timehistory, or crash pulse. In turn, the crash pulse and seat pitch affect the velocity with which an occupant strikes the forward seat back, and the velocity affects the severity of the injuries incurred.

In designing a crashworthy commuter seat, the variables associated with the operating environment, which are independent of the seat design, must be considered. These variables include the structural design of the rail car and the seat pitch and orientation. For CEM equipment, the location of the car within the train is also a factor to consider.

The acceleration time history data for different equipment types and collision scenarios have been calculated from pretest model predictions and measured during full-scale impact tests $[3,4,5]$. Car body acceleration under impact conditions has significant variation associated with it, making it difficult to evaluate and compare severity among different scenarios. By integrating the acceleration time history to calculate velocity and displacement time histories, the resulting velocity versus displacement graph can provide a better comparison of multiple sets of data. Additionally, a simplified triangular crash pulse can be calculated that will result in nearly the same impact velocity, and will be much easier to simulate in a sled test.

Figure 1 contains acceleration-time histories that correspond to the leading cab car and first coach car in a trainto-train collision of CEM equipment, along with triangular 8-G and 12-G crash pulses. It is difficult to evaluate the severity of each curve from the acceleration plots alone.

Figure 2 contains the velocity versus displacement curves that correspond with the acceleration curves in Figure 1. From this graph, it is easy to observe that the acceleration curves corresponding to the leading cab car and the 12-G pulse result in nearly the same relative velocity at any point along the horizontal axis. Likewise, the acceleration curves corresponding to the first coach car and the 8-G pulse result in approximately the same relative velocity, although the 8-G pulse is somewhat more severe.

When designing seats to be used in a leading CEM cab car, the dynamic test requirements specify a $12-\mathrm{G}$ 0.25-second crash pulse. For seats in CEM cars other than a leading cab car and for all conventional cars, an 8-G 0.25-second crash pulse is specified, as per American Public Transportation Association (APTA) SS-C\&S-016-99, Rev. 1, Standard for Row-to-Row Seating in Commuter Rail Cars.

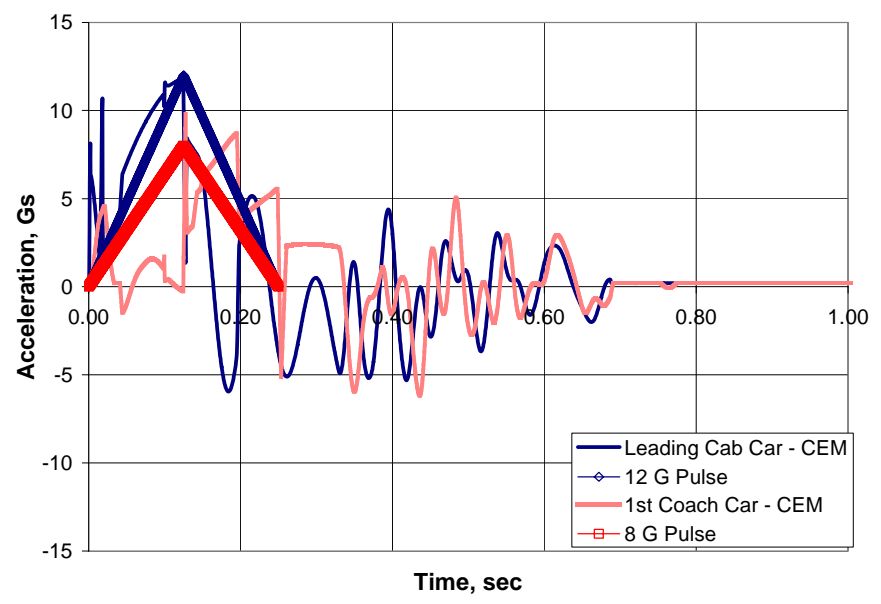

Figure 1. Acceleration Time History

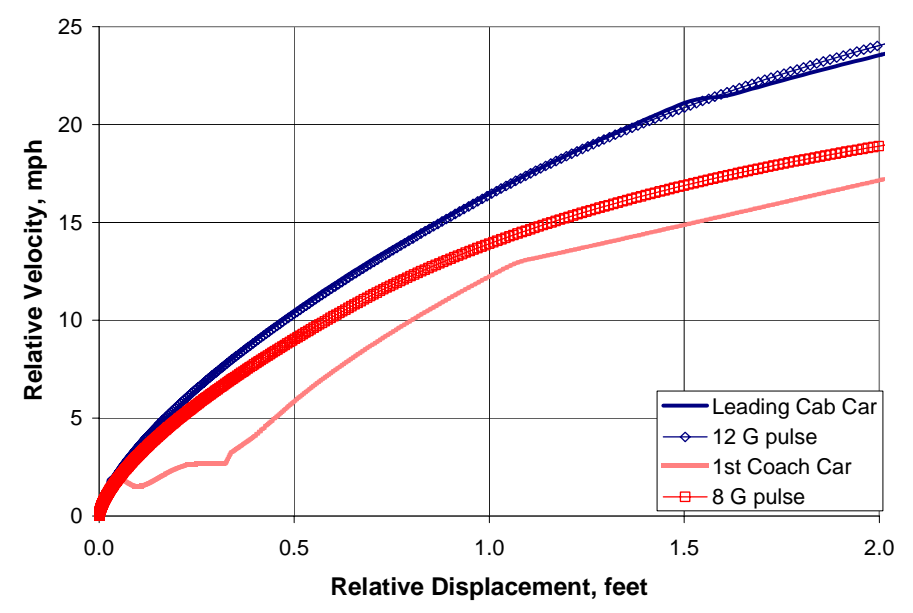

Figure 2. Relative Velocity versus Relative Displacement 


\section{PERFORMANCE-BASED DESIGN REQUIREMENTS}

Federal regulations [6] and industry standards [7] address crashworthiness requirements for commuter seats used in conventional equipment, as well as service, fabrication, and ergonomic requirements. This paper focuses on more stringent crashworthiness requirements that have been developed to evaluate the prototype seat, which is being designed for use in CEM cab cars. Static and dynamic tests will be conducted to determine if the seats meet the crashworthiness requirements. The following section will describe the test conditions necessary to develop and evaluate the seat design, followed by the occupant response requirements and the seat performance requirements.

\section{Test Conditions}

Static and dynamic testing of the commuter seats should be performed in accordance with the test requirements specified in the Appendix. The static test is designed to characterize the force versus deformation behavior of the seat back. The dynamic sled tests are designed to simulate the conditions of an inline train-to-train collision.

The dynamic test will measure the forces and accelerations experienced by a Hybrid III $50^{\text {th }}$ percentile male ATD during collision conditions expected in different collision scenarios. The recommended crash pulse and seat orientation will vary depending upon the intended service conditions for a particular commuter seat. For instance, if a commuter seat is developed for service in a conventional train, the existing 8G, 0.250 second crash pulse shall apply. If a seat is to be used in the leading cab car of a CEM train, a 12G, 0.250-second crash pulse shall apply. If a seat is to be used in cars behind the leading car of a CEM train, the 8G, 0.250-second crash pulse shall apply.

\section{Occupant Response}

During the dynamic test conditions, the injury measurements taken for all of the instrumented ATDs must meet the following criteria, which are defined in CFR 49 Part 571, Section 208: Occupant Crash Protection, typically used in the automotive industry:

- HIC15 must not exceed 700

- Nij must not exceed 1.0

- Neck tension must not exceed $937 \mathrm{lbf}(4,170 \mathrm{~N})$

- Neck compression must not exceed 899 lbf $(4,000 \mathrm{~N})$

- Chest deceleration must not exceed $60 \mathrm{G}$ over $3 \mathrm{~ms}$

- Axial femur loads must not exceed 2,250 lbf (10,000 N)

All ATDs must be also be compartmentalized during dynamic test conditions. The APTA standard (APTA SS-C\&S016-99, Rev. 1) defines compartmentalization as "a strategy for seat design in which the seat provides enough stiffness to absorb all or a substantial portion of the kinetic energy of a passenger thus preventing a tertiary impact. An occupant is compartmentalized when the torso is confined within the perimeter defined by the front edge of the front row seat pan, the full width of the aisle, and the seat back surface of the launch seat.” The shaded area in Figure 3 shows the definition of compartmentalization according to the APTA Standard.

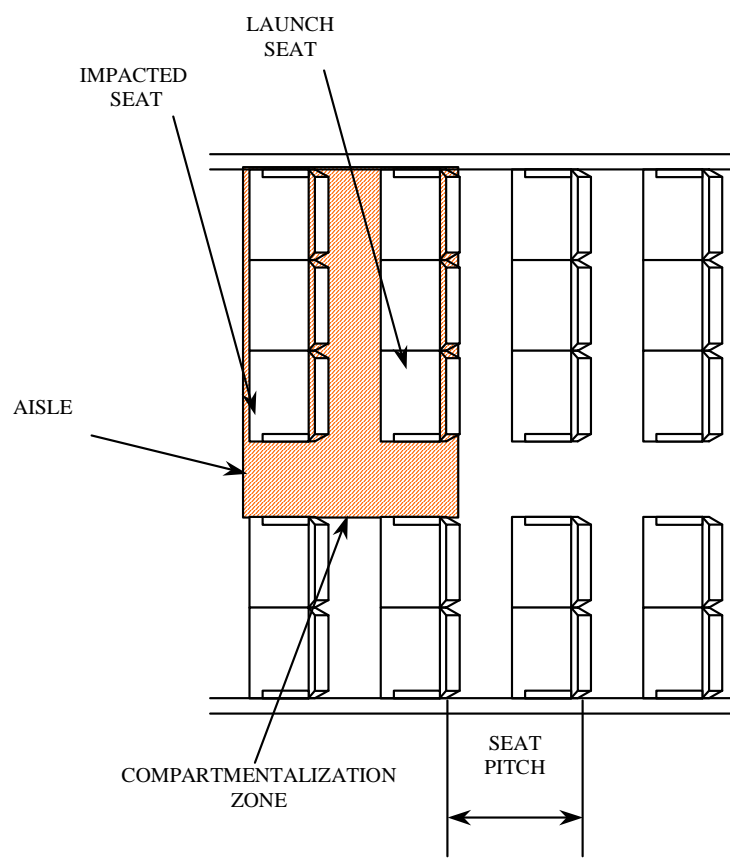

Figure 3. Compartmentalization Zone Defined

\section{Seat Performance}

During dynamic testing the seat must remain attached to the test sled at all attachment points. The deformation of the seat must not result in any sharp edges with which the occupant may come into contact. Permanent seat deformations will be measured on the critically loaded seat after dynamic tests. Significant measuring points will be identified and marked on the test seat, and their positions measured in the lateral, vertical, and longitudinal directions relative to fixed points on the test fixture. Measurement of the selected points will be recorded before and after the tests. The permanent seat deformations must not significantly impede an occupant from standing and exiting the seat. The following defines allowable permanent seat deformations.

\section{Longitudinal Direction}

The permanent longitudinal deformation of a seat will not exceed $8 \mathrm{in}$. The measurement will be made at the forwardmost hard point(s) of the seat at a height up to and including the armrest. The forward-most surface of a seat back must not deform to a distance greater than the forward-most hard structure on the seat. See Figure 4.

\section{Downward Direction}

No limitation exists for permanent downward deformation, provided it can be demonstrated that the feet and legs of occupants will not be entrapped by the deformation.

\section{Lateral Direction}

The permanent lateral deformation of a seat towards an aisle will not exceed $3 \mathrm{in}$. at heights less than $25 \mathrm{in}$. above the 
floor and will not exceed 4 in. at heights 25 in. or more above the floor. See Figure 5.

\section{Tray Tables}

If tray tables deploy during the test, it must be possible to return them to their stowed position subsequent to the test with no more than the force required to stow the tray tables before the test.

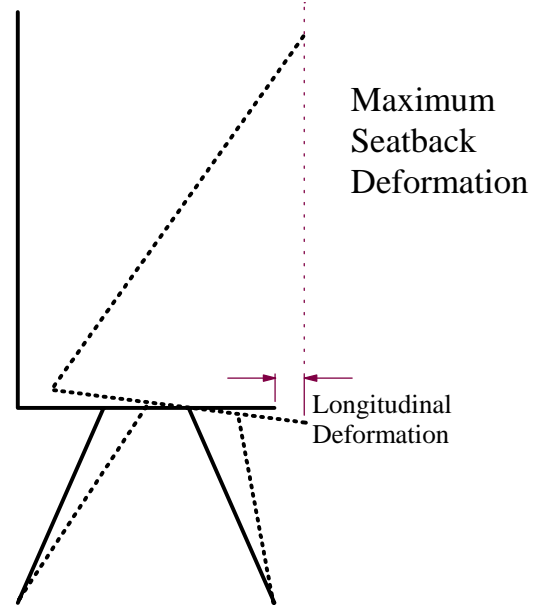

Figure 4. Longitudinal Deformation

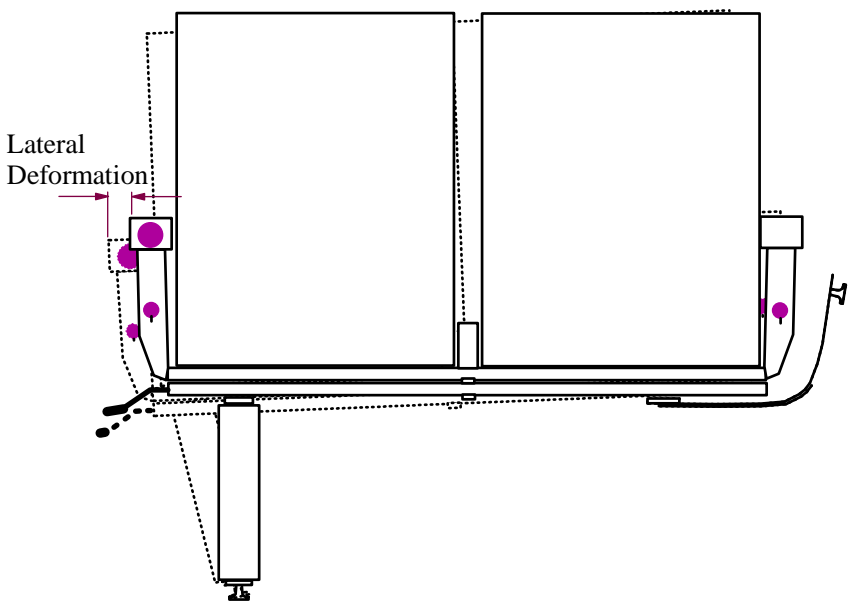

Figure 5. Lateral Deformation

\section{DESIGN GUIDELINES AND STRATEGIES}

Given the collision environment and the performance-based requirements that the seat design must meet, several strategies may be employed to achieve a successful design. The number one priority for the seat design is to absorb the kinetic energy of the occupant in a way that minimizes injury to the head, neck, chest, and legs. This energy must be absorbed such that the person is compartmentalized and the injury levels are kept to a minimum.

A concept generation session has been held to generate ideas, such as systems, mechanisms, or materials, that together define a solution to the design of interest. The ideas can be pulled together into concepts which usually fall into several methods or strategies that are focused on meeting the requirements. For the seat design concepts, these strategies can be grouped into the following categories:

- Seat orientation

- $\quad$ Seat to car attachments

- Seat back/seat pan deformation

- $\quad$ Energy absorbing protective surfaces on seat back

- Increase of the seat back height

\section{Seat Orientation}

The seat orientation refers to whether the seats are forwardfacing or rear-facing. Due to the more severe acceleration pulse expected for the leading cab car in a CEM-based train in an inline collision, one possible strategy to minimize secondary impact occurrences is to have all the seating of the leading cab car rear-facing. The seats and the attachments would need to be designed to withstand the 12-G load, but the occupant would be less likely to suffer serious injuries due to secondary impacts. This strategy could be used in conventional cars as well.

\section{Seat-to-Car Attachments}

One way to absorb the secondary impact energy is to allow the seat attachments to crush or plastically deform in a controlled manner. This allows the seat to move in either the fore or aft direction once the impact load reaches a prescribed minimum value. Shock absorbers could be used to absorb energy instead of crushing or plastically deforming material. The limited space for displacement of the seat can reduce the effectiveness of absorbing the necessary energy and can increase the load seen by the occupant, independent of the actual method used to absorb energy. For this strategy to be successful on its own, the force needed to cause the seat to displace must be low enough to meet the required injury criteria, given the seat back is not absorbing any energy. A low force coupled with a small displacement tends to limit the energy that can be absorbed.

This strategy must also account for the position of the occupants. An occupant seated in the middle seat might generate a different response than one seated at the aisle or at the window due to the location of the attachments. Distribution of the impact load to each of the attachments must be considered.

Another concern for this strategy is whether it will work when each seat in the row is not occupied. It will be difficult to absorb energy for one, two, or three occupants if the seat is of a uni-frame construction and not modular. This could result in more severe injuries for one or two occupants seated in a row compared to three occupants. Conversely, if the design is tuned to less than three occupants seated in the row, risk of not meeting the requirements for three occupants exists.

\section{Seat Back/Seat Pan Deformation}

Another way to absorb the secondary impact energy of the seated, unrestrained occupants is to allow the seat back and/or the seat pan to deform. This may be accomplished in a number of ways. One way is to allow the seat back to rotate through a controlled angle and absorb energy at the seat back/seat pan 
interface with a rotational energy absorber. This may not be the most efficient method of energy absorption for this situation but could succeed.

Another method of absorbing energy is to allow the frame structure of the seat to deform while under load from the occupant. This method could be extended to provide different amounts of deformation along the length of the seat back by including specific changes in frame structure or by using a continuously varying structure. For example, near where the head impacts the back of the seat, there may be a less stiff frame structure than closer to the seat pan. The seat back could also act like a catcher's mitt to keep the person in his/her seat/row position while it deforms to absorb the impact energy.

In each of the tests that have been conducted, it has been noted that the first things to hit the seat in front of the occupant in a forward-facing seat configuration are the occupant's knees. This causes the upper body to rotate at the hips causing a rotational velocity that increases the secondary impact velocity of the head. This pivoting action can also increase the loads on the neck due to the orientation of the body and the distinctly separate times the head and chest impact the seat back.

Figure 6 was taken from high-speed film of the full-scale test occupant experiment for an intercity seat arrangement. Figure 6a shows the occupants after sliding forward with the upper body relatively straight and the knees impacting the seat back of the seat in front of them. Figure 6b shows the head impacting the seat back a few milliseconds later with the upper torso having rotated forward. This rotation increases the secondary impact of the head on the seat back, as well as placing the head and neck in a more injury prone position.

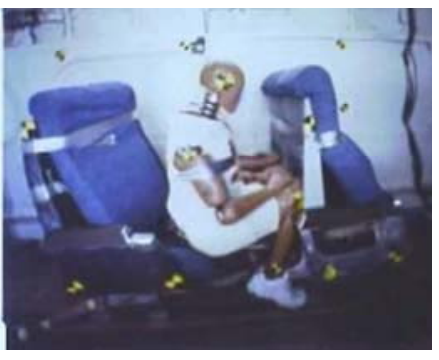

Figure 6a. Knee Impact

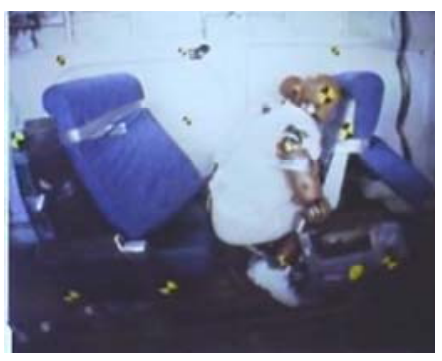

Figure 6b. Head Impact
One way to help reduce the added rotational velocity and the time difference for head and chest impact with the seat back is to design a way for the knees to penetrate the back of the seat pan with minimal resistance (see Figure 7). This will allow the body to translate uniformly and could allow the head and chest to impact the back of the seat at approximately the same time, thereby spreading the load on the body and possibly reducing the loads on the neck. Meeting the operational requirements, especially loads on the back of the seat near the level of knees, may be difficult. If the load is too low, maintenance issues may be more prevalent.

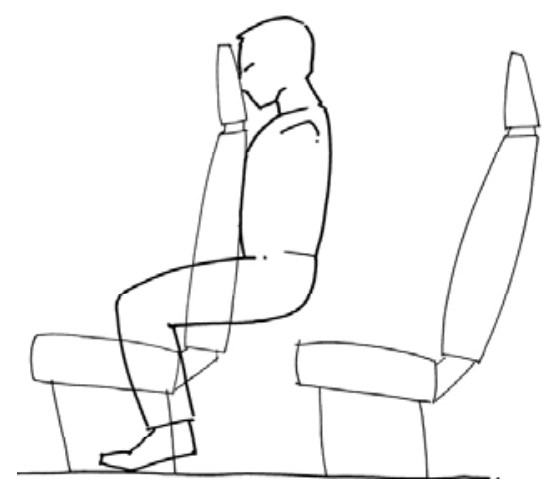

Figure 7. Schematic View of Occupant Impact with Knees Penetrating the Seat Back

The deformation or rotation of the seat back, whether in a forward- or rear-facing configuration, must be controlled to keep the seat back from collapsing totally and allowing the occupant to be propelled into the next row of seats. In addition, the position of the seat back after rotation should not impede the egress of the occupant. Strategies to limit the rotation may include stops specifically designed to limit rotation, or a controlled deformation of the seat back that becomes selflimiting.

\section{Energy Absorbing Protective Surfaces on Seat Back}

Not all of the strategies are meant to solve the problem on their own. In many cases, several strategies may be combined to complete the successful design. One such strategy is focused on providing a surface that can be impacted with minimal injury locally to the occupant. Though it would be ideal if this strategy could independently absorb the impact energy of the occupant, limitations on its thickness make it unlikely to meet all of the injury requirements. For example, padded surfaces can be used to help minimize the local injury to the face or the knees. The covering of the padded surface, especially if it is placed mid-height to the top of the seat back, can be made from a material that has a relatively high coefficient of friction, compared with a smooth plastic surface. This could help keep the occupant compartmentalized. In addition, contours in the surface may also provide compartmentalization benefits by guiding the legs/torso onto the seat back.

\section{Increase Seat Back Height}

One strategy to increase the likelihood of compartmentalization is to increase the height of the seat back to provide a better barrier to climbing. This strategy would in all likelihood be combined with some sort of controlled displacement of the seat back and could be helpful in forwardand rear-facing seats.

For rear-facing seats, the seat back structure must be able to deform while keeping the person compartmentalized and protecting the head and neck. Since the occupant is already seated with the back pressed against the seat back, there is little time for relative velocity of the occupant with respect to the seat to develop. Loads on the neck can be severe, however, if the head is not supported by the seat back. Figure 8a shows the occupant's initial position for a typical seat where the 
occupant's head is not supported by the seat back. Figure $8 b$ shows the occupant after impact, where the neck is bent back over the seat back. Taller seat backs are one way to reduce the risk of neck injuries.

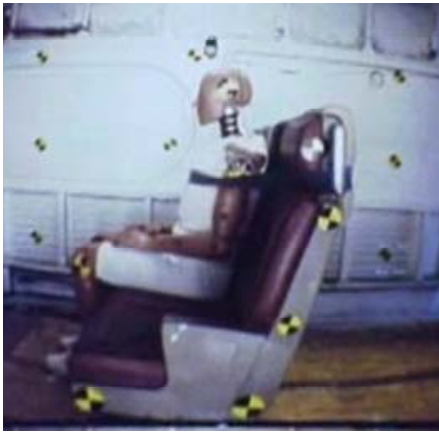

Figure 8a. Initial Position

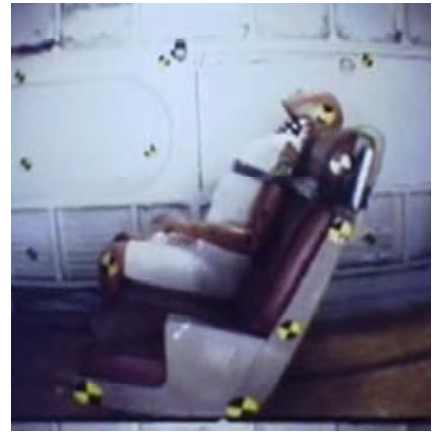

Figure 8b. After Impact
The use of modular frames may be advantageous in designs that use controlled seat back deformation because the number of seated occupants and their position will not affect the performance of the seat back. This is also true for forwardfacing seating configurations.

These are a few of the strategies that may be used in a commuter seat design to help protect seated occupants involved in rail collisions. Many of these strategies are being employed in the details of a prototype commuter seat design. Computer analyses and the upcoming full-scale CEM train-to-train test will demonstrate the effectiveness of these strategies in meeting the seat design requirements.

\section{PRELIMINARY OVERVIEW OF OPTIMIZED COMMUTER SEAT DESIGN}

During the design phase, analyses are conducted to determine if the seat meets the design requirements. Results from preliminary computer models are presented in this section.

An occupant model with rear-facing seats was used as a strategy to minimize occupant severity under the 12-G impact conditions. An occupant model with forward-facing seats was used under the 8-G impact conditions. The main differences between the prototype seat and existing seats are:

- Seat back is 4 in. taller

- Force versus deformation behavior of seat back was modified, including a hard stop

- Modular seats versus an integrated seat back

The modeling results indicate that the improved neck support from the taller seat back improves the maximum Nij by $25 \%$ in the rear-facing configuration. The modified force versus deformation behavior of the seat back improved the maximum HIC by $25 \%$ and the maximum chest Gs by $20 \%$ in the forward-facing configuration. The other injury criteria are modestly better with the prototype seat design. All injury criteria are well below the criteria, and the ATDs are compartmentalized.

\section{SUMMARY AND CONCLUSIONS}

This paper describes performance-based design requirements that can be used to improve interior crashworthiness for occupants seated in commuter rail seats. The process of developing a new seat design to meet crashworthiness design requirements has been described. Test requirements have been defined against which the proposed design can be evaluated. Design guidelines and strategies have been provided to assist seat designers in developing improved energy-absorbing commuter seats.

Seat design requirements for improved interior crashworthiness have been driven by the increased severity of the collision environment in CEM cab cars. However, the collision safety of all commuter rail service can be improved by applying these design requirements to commuter seats on any type of rail equipment.

\section{ACKNOWLEDGMENTS}

The research discussed in this paper was performed as part of the Equipment Safety Research Program sponsored by the Office of Research and Development of the Federal Railroad Administration. The authors would like to thank Dr. Tom Tsai, Program Manager, and Ms. Claire Orth, Division Chief, Equipment and Operating Practices Research Division, Office of Research and Development, Federal Railroad Administration, for their support. Additional thanks go to A. Benjamin Perlman, Professor at Tufts University, for assistance in editing this paper.

\section{REFERENCES}

[1] VanIngen-Dunn, C., "Passenger Rail Train-to-Train Test Volume II: Summary of Occupant Protection Program,” U.S. Department of Transportation, DOT/FRA/ORD-03/17.2, July 2003.

[2] Severson, K., Parent, D., Tyrell, D., “Two-Car Impact Test of Crash Energy Management Passenger Rail Cars: Analysis of Occupant Protection Measurements," American Society of Mechanical Engineers, Paper No. IMECE2004-61249, November 2004.

[3] Tyrell, D., Severson, K., Zolock, J., Perlman, A.B., "Passenger Rail Two-Car Impact Test Volume I: Overview and Selected Results," U.S. Department of Transportation, DOT/FRA/ORD-01/22.I, January 2002.

[4] Tyrell, D., "Passenger Rail Train-to-Train Impact Test Volume I: Overview and Selected Results,” U.S. Department of Transportation, DOT/FRA/ORD-03/17.I, July 2003.

[5] Jacobsen, K., Tyrell, D., Perlman, A.B., “Impact Tests of Crash Energy Management Passenger Rail Cars: Analysis and Structural Measurements," American Society of Mechanical Engineers, Paper No. IMECE2004-61252, November 2004.

[6] Code of Federal Regulations, Title 49, Part 238, Passenger Equipment Safety Standards, Section 435, October 2003.

[7] APTA SS-C\&S-016-99, Rev. 1, Standard for Row-to-Row Seating in Commuter Rail Cars, The American Public Transportation Association, Washington, DC. 


\section{APPENDIX-QUASI-STATIC AND DYNAMIC TEST REQUIREMENTS}

\section{Test Objective}

The objective of these test requirements is to evaluate the crashworthiness performance of commuter rail passenger seats under static and dynamic conditions. The static test will measure the force versus deformation behavior of the seat back, which is critical to limiting the forces experienced by an occupant and to compartmentalizing an occupant. The dynamic tests will measure the forces and accelerations experienced by an occupant during collision conditions expected in a train-totrain collision of CEM or conventional equipment.

\section{Approach}

Quasi-static testing will be conducted first to measure the force versus deformation behavior of the seat back and to determine the force levels required to cause gross failure of the seat and/or its attachment points. Dynamic sled tests will be conducted to evaluate occupant protection and seat performance.

\section{Static Testing}

The force versus deformation behavior of the seat back will be measured using a hydraulic loading ram. A single commuter seat row will be fastened to seat track, which is fastened to a sub-floor (and potentially a sub-wall), which is mounted on four tri-axial load cells (see Figure A.1). A monotonically increasing load will be applied to the back of the seat back in a horizontal direction. The load will be applied at a point approximately $12 \mathrm{in}$. below the top of the seat back. The seat will be tested to gross failure (significant permanent deformation or component failure). Horizontal string potentiometers will be used to measure the deflection at the top, center, and bottom of the seat back and the front of the seat pan. The load application bar will span the width of all seat positions.

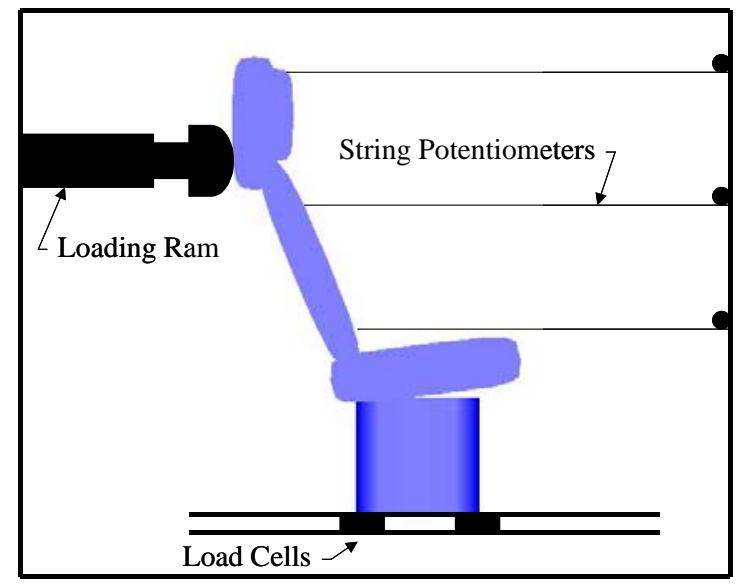

Figure A.1. Schematic of Quasi-Static Test Configuration

\section{Dynamic Testing}

Two dynamic sled tests will be conducted. For each test, two commuter seats facing the same direction will be fastened to seat track, which is fastened to a sub-floor (and potentially a sub-wall), which is mounted to four triaxial load cells. The seat pitch shall be the same as is intended in service. Instrumented Anthropomorphic Test Devices (ATDs) will be placed in each seat position of the seat row such that they are facing the next seat row.

One test will be conducted with a fifth percentile Hybrid III female ATD in each seat position. Another test will be conducted with a $95^{\text {th }}$ percentile Hybrid III male ATD in each seat position. The ATDs will be instrumented to measure forces and accelerations so that injury criteria can be calculated. A successful test in these extreme cases will demonstrate that the seat can compartmentalize occupants and keep injury criteria below allowable limits. Each ATD shall be instrumented. See Figure A.2 for a schematic of the sled configuration.

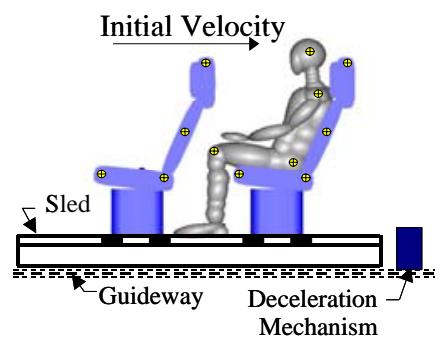

Rear-Facing Seats

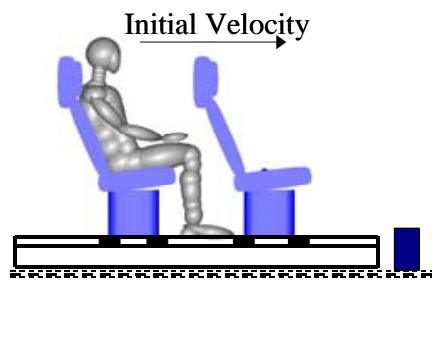

Forward-Facing Seats

\section{Figure A.2. Schematic of Dynamic Test Configuration}

The seats will be tested according to the intended service conditions, including car type (cab car or coach car), car structure (conventional or CEM), seat pitch, and seat orientation (forward- or rear-facing).

Each dynamic test will be conducted with a triangular crash pulse (i.e., acceleration time history) with a 0.25 -second duration. The peak of the crash pulse will be 12 Gs for seats used in CEM cab cars. The peak of the crash pulse for all other seats will be 8 Gs. These crash pulses will approximate the longitudinal motion expected under the respective collision conditions. See Figure A.3 for a plot of the crash pulses.

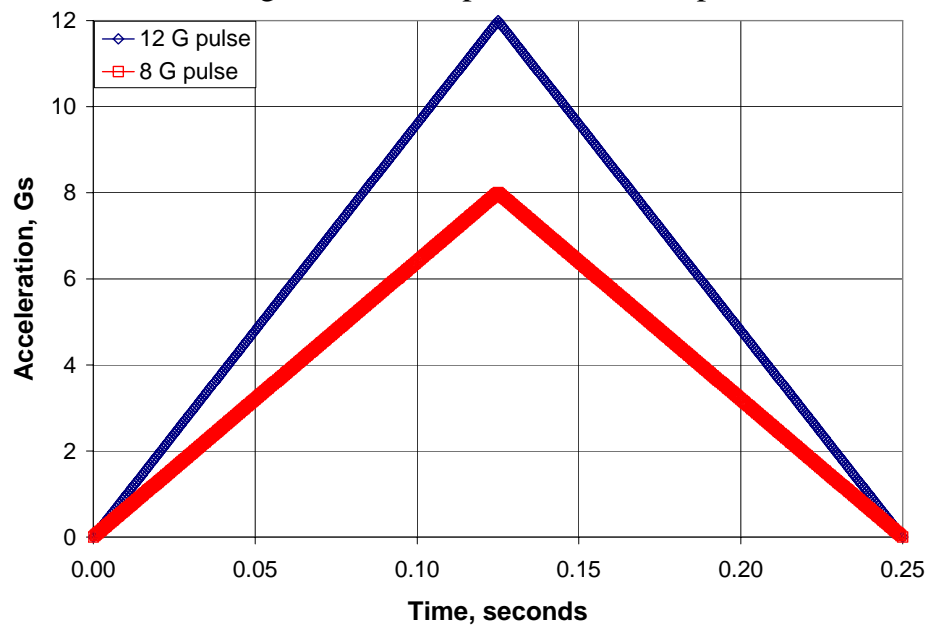

Figure A.3. Test Crash Pulses 